\title{
MEMÓRIA E PATRIMÔNIO CULTURAL: A PROTEÇÃO JURÍDICA, A GESTÃO E O ACESSO AOS DOCUMENTOS HISTÓRICOS BRASILEIROS
}

\author{
Felipe Braga de Oliveira ${ }^{1}$
}

RESUMO: Trata-se de pesquisa sobre o ambiente cultural, especificamente sobre a proteção do patrimônio cultural documental. A tutela da memória nacional, bem de todos, é estabelecida na Constituição Federal e necessita de regulamentação própria, tais como as Leis da Política Nacional de Arquivos Públicos e Privados e de Acesso à Informação. Através de revisão bibligráfica, busca-se elucidar o acerca da construção da memória nacional por meio da gestão documental no Brasil, o acesso público à documentação bem como suas restrições e critérios de sigilo ao longo de alguns governos.

Palavras-chave: Memória. Patrimônio cultural. Proteção jurídica. Gestão documental. Lei de Acesso à Informação.

\section{MEMORY AND CULTURAL HERITAGE: LEGAL PROTECTION, MANAGEMENT AND ACCESS TO BRAZILIAN HISTORICAL DOCUMENTS}

\begin{abstract}
This is research on the cultural environment, specifically on the protection of cultural documentary heritage. The protection of the national memory, collective assets, is established in the Federal Constitution and needs its own regulation, such as the Laws of the National Policy of Public and Private Archives and Access to Information. Through a bibliographical revision, it is sought to elucidate the about the construction of the national memory through documentary management in Brazil, the public access to the documentation as well as its restrictions and secrecy criteria n the course of some governments.
\end{abstract}

Keywords: Memory. Cultural heritage. Legal protection. Document management. Law on Access to Information.

\section{INTRODUÇÃO}

O meio ambiente cultural, interface do direito ao meio ambiente, tomou maior espaço na discussão jurídica a partir da Constituição Federal de 1988. Esta, que é lei sem número por sua unicidade, lei maior e primeira, destinou dispositivos especialmente para a proteção do

\footnotetext{
${ }^{1}$ Mestre em Direito Ambiental pela Universidade do Estado do Amazonas. Especialista em Direito Público e Bacharel em Direito pela UNINORTE. Historiador pela Universidade Federal do Amazonas.
} 
patrimônio cultural, do fazer e do viver, do pensar e do criar, dos comportamentos e hábitos, dos documentos.

É a partir desse contexto, de nova ordem jurídica, que as novas bases devem ser alçadas quanto à proteção dos bens culturais. A CF/88, que é uma mesa redonda, roteiro e agenda da nação, fazendo aflorar e multiplicar princípios específicos aos quais as leis devem se orientar.

Os documentos, nesse sentido, tornam-se primordiais nas fontes de construção da história (e da sociologia, do direito, das ciências humanas e sociais). Sua proteção, portanto, toma novas vertentes após os ditames da Lei Maior.

A gestão documental e o acesso à informação recebem diretrizes e normativas específicas, cuidando-se da coisa pública e também dos arquivos privados, em suma cujo interesse público é inequívoco. A Lei de Arquivos Públicos e Privados delineia os caminhos a serem seguidos, sendo completado pela Lei de Acesso à Informação, importante passo dado na abertura da caixa preta que se tornam as instituições públicas, em suma do Poder Judiciário.

A documentação histórica constitui tal patrimônio e deve ser preservada, independentemente de sua origem pública ou privada, tendo em vista que se enquadra no arcabouço de bens móveis do país, possuindo, de mais a mais, Política Nacional instituída em Lei (Lei no 8.159/1991).

Os documentos históricos recebem proteção constitucional e infraconstitucional por fazerem referência à identidade, à ação e à memória dos diferentes grupos formadores da sociedade brasileira. Nesse sentido, erige a problemática: se a defesa e preservação do meio ambiente cultural tem como um dos seus vieses a proteção dos documentos históricos, quais regramentos legais tutelam tais documentos? Como se dá a gestão documental e qual a efetividade dessas medidas jurídicas?

Com o fim de traçar um caminho a ser seguido, sistematizando as atividades para alcançar o objetivo geral desta pesquisa, utiliza-se o método bibliográfico. Cumpre destacar que, não há pesquisa que parta do marco zero, ainda mais quando se têm trabalhos de realce nacional e internacional acerca do tema proposto, motivo pelo qual será realizada uma revisão bibliográfica acerca do tema.

Em relação aos métodos de procedimento, sendo esta pesquisa voltada para a área de Ciências Sociais, será realizada, em síntese, análise bibliográfica e revisão de livros gerais e específicos sobre a temática proposta, bem como levantamento de informações, em páginas da 
rede mundial de computadores (internet) que contenham conteúdos jurídicos, voltados para a publicação de doutrinas, obras e jurisprudências, além de periódicos especializados.

O presente artigo, nesse sentido, tratará da memória enquanto bem de todos, delimitando-se aos documentos considerados históricos e, consequentemente, dotados de proteção jurídica. Nesse diapasão, aludem-se às considerações capitais sobre a gestão documental e a legislação que o cerca, como a Política Nacional de Arquivos Públicos e Privados e a Lei de Acesso à Informação. As determinações da arquivística, aqui, se tornam primordiais.

\section{MEMÓRIA, PATRIMÔNIO E GESTÃO DOCUMENTAL}

1. A memória como patrimônio cultural

O patrimônio cultural é formado de bens tangíveis móveis, dos quais se destacam os objetos de arte, objetos litúrgicos, livros e documentos, fósseis, coleções arqueológicas, acervos museológicos, documentais e arquivísticos, dos quais são classificados conforme os Livros do Tombo, cuja responsabilidade é do Instituto do Patrimônio Histórico e Artístico Nacional (IPHAN).

O instituto foi criado em 13 de janeiro de 1937, ainda com Getúlio Vargas na chefia do Poder Executivo, por meio da Lei $n^{0}$ 378, com o objetivo de proteger os bens cultuais considerados representativos. Nesse sentido, asseverava o dispositivo 46 da Lei de criação do IPHAN: “fica creado o Serviço do Patrimonio Historico e Artístico Nacional, com a finalidade de promover, em todo o Paiz e de modo permanente, o tombamento, a conservação, o enriquecimento e o conhecimento do patrimonio historico e artístico nacional”.

Todo esse arcabouço instituído para a conservação do patrimônio cultural brasileira tem um objetivo principal: manter viva e possível a memória. Segundo Sandra Pelegrini (2009, p. 33), memória conceitua-se como:

Disposição de reter, armazenar informações, sentimentos e imagens no cérebro humano. Elemento constituinte da identidade individual e coletiva. Relacionada às culturas e aos modos de entender o mundo, essencial para a continuidade das práticas culturais e para a reconstrução de si. 
As ciências sociais e humanas se debruçam reiteradamente sobre o conceito de memória. Não se tem, por conseguinte, o objetivo de contribuir para a construção de um novo conceito. A bem da verdade, o que se almeja é utilizar-se de um arcabouço teórico já consolidado, discorrendo, por fim, sobre a memória como integrante do patrimônio cultural e, consequentemente, como bem constitucionalmente protegido.

Nesse sentido, memória “é um conceito que pode ser associado tanto à possibilidade de lembrar algo que ocorreu no passado, como à capacidade de guardar experiências em nosso próprio corpo-mente ou outros dispositivos materiais” (ZARANKIN e SALERNO, 2015, p. 261).

Segundo Andrés Zarankin e Melisa Salerno (2015, p. 261),

a memória jamais pode oferecer uma visão acabada do passado. Pelo contrário, compõe-se de uma série de traços ou vestígios a partir dos quais se gera um recorte particular do sucedido. Posteriormente, os fragmentos se ordenam e conectam numa sequência narrativa - que não difere, necessariamente, da estrutura de relato.

Nessa esteira de pensamento, a memória pode adquirir diversas expressões, sejam pessoais ou coletivas, oriundas de vestígios materiais e imateriais. No plano das lembranças, a humanidade pode construí-las “a partir de vivências próprias ou alheias nas quais as pessoas interagem de formas específicas com a materialidade do mundo” (ZARANKIN e SALERNO, 2015, p. 263). Já no que diz respeito ao mundo natural, à materialidade, os objetos e a documentação podem despertar, reforçar ou construir lembranças em circunstâncias distintas.

Memória é o que se reteve do passado ou se quer guardar sobre qualquer coisa. A memória cultural é a conservação de fatos ou ações do passado ou do presente visando ao tempo futuro” (MACHADO, P., 2013, p. 1093).

A memória constrói identidade e estamos dia após dia buscando resgatá-la, reorientála, firmá-la. "Vivimos en tiempos en los que la apelación a la memoria aparece en todas partes. Se lucha por la memoria, se recuerda, se preserva, se marca, se anuncia, se restaura” (LORENZ, 2009, p. 7). Tudo isso acontece porque “todo exercício de memória é realizado a partir de mediações e representações, trazendo essa ambiguidade que lhe é constitutiva entre recordar e reconstruir o passado, seja pelas lacunas apresentadas por este, seja pelas suas múltiplas leituras possíveis” (SOARES., QUINALHA., 2010, p. 253). 
Jacques Le Goff (1990, p. 476), no sempre lembrado "História e Memória”, discorre que "a memória é um elemento essencial do que se costuma chamar identidade, individual ou coletiva, cuja busca é uma das atividades fundamentais dos indivíduos e das sociedades de hoje, na febre e na angústia”. É enfático o autor (1990, p. 476), ainda, ao afirmar que:

A memória coletiva é não somente uma conquista, é também um instrumento e um objeto de poder. São as sociedades cuja memória social é sobretudo oral ou que estão em vias de constituir uma memória coletiva escrita que melhor permitem compreender esta luta pela dominação da recordação e da tradição, esta manifestação da memória.

Finalizando, o supracitado autor assevera que (p. 477), “a memória, onde cresce a história, que por sua vez a alimenta, procura salvar o passado para servir o presente e o futuro. Devemos trabalhar de forma a que a memória coletiva sirva para a libertação e não para a servidão dos homens”.

A memória, nesse sentir, é meio para a compreensão dos modos de viver e fazer da sociedade e de um Estado, inclusive no que tange às opções políticas daquilo que deve ser lembrado ou esquecido, legitimando grupos sociais para o exercício da memória, formando-se uma memória coletiva. Destaque-se que esta memória pode ser construída por meio de variadas fontes, dentre as quais a que está no cerne deste trabalho, a documentação.

Não obstante, resta clarividente pelo outrora exposto, que a memória está inserida como patrimônio a ser resguardado pelo Estado brasileiro. A Constituição da República sublinha tal afirmação, especialmente em seu dispositivo 216, ao ordenar que constituem patrimônio cultural brasileiro os bens de natureza material e imaterial, portadores de referência à identidade e à memória dos diferentes grupos formadores da sociedade brasileira.

São vastos diversificados os bens portadores de referência à memória dos diferentes grupos formadores da sociedade brasileira, dentre eles podem ser elencadas as formas de expressão, a língua, a literatura, a música, a dança, as festas religiosas, o folclore, os modos de viver, de criar e viver, as criações científicas, as obras, objetos, documentos, edificações e demais espaços destinados às manifestações artístico-culturais, os conjuntos urbanos e sítios arqueológicos etc. 
Não se nega a subjetividade na análise de quais bens serão considerados formadores da sociedade. O olhar estatal poderá ser voltado apenas às obras de Aleijadinho, Machado de Assis ou a Carta de Pero Vaz de Caminha, negligenciando-se outras manifestações e documentos que demonstram a existência e tradições de um grupo menor de pessoas, integrantes, como não, da compreensão do Brasil hodierno.

No entanto, sem adentrar nesta celeuma, importa frisar que a memória é parte integrante do patrimônio cultural, devendo, para isto, ser o Estado o garantidor dos bens ligados à formação e constituição do Brasil, o que, nesse contexto, dá a ele a responsabilidade pela documentação histórica, a qual, em conjunto ou separadamente, poderão ser objeto de (re)construção da memória individual e coletiva.

A memória e a necessidade de interpretação dos acontecimentos sociais, inclusive dos mais nefastos, passam, dia após dia no Brasil, por um processo de latência de memória, como cunhou Inês Soares (2013, p. 2) em texto no qual expunha sobre a ditadura militar. Para isso, a autora citada abarca diversos meios pelos quais a memória pode ser tutelada, quais sejam: tombamento, inventário, desapropriação, pesquisas arqueológicas e registro.

É de se lembrar que estes meios não são taxativos, mas exemplificativos, podendo o legislador e/ou o administrador utilizar-se de outras formas de acautelamento. A necessidade de "suportes de toda a demanda por verdade e memória - documentos, fotografias, lugares e objetos [...] são elementos que integram os bens culturais: arquivos, memoriais, cemitérios (clandestinos ou não), filmes, livros dentre outros” (SOARES, 2013, p. 4).

Necessário, para os fins deste estudo, um olhar mais direto ao patrimônio cultural ao qual se quer enfatizar: os documentos históricos.

2. Documentos históricos: delimitação e proteção.

Em estudo sobre documento, história e memória, Merlo e Konrad (2015, p. 27), já nas linhas introdutórias, questionam e afirmam: “o que seria de uma sociedade, hoje, sem seus documentos? Os documentos são a essência de uma organização, a memória de uma sociedade”. É salutar realçar, então, que o “documento é um suporte material do saber e da memória da humanidade” (GUINCHART e MENU, 1994, p. 41).

Nos conceitos ligados à arquivologia, o documento é considerado "peça escrita ou impressa que oferece prova ou informação sobre um assunto ou matéria qualquer” (GOMES, 
1967, p. 5). Para Marielena Paes (2006, p. 26), trata-se o documento de "registro de uma informação independente da natureza do suporte que a contém”.

De forma mais abrangente, Schellenberg (2006, p. 41) conceitua documento, novamente para a arquivologia, como sendo:

Todos os livros, papéis, mapas, fotografias ou outras espécies documentárias, independentemente de sua apresentação física ou características, expedidos ou recebidos por qualquer entidade pública ou privada no exercício de seus encargos legais ou em função das suas atividades e preservados ou depositados para preservação por aquela entidade ou por seus legítimos sucessores como prova de suas funções, sua política, decisões, métodos, operações ou outras atividades, ou em virtude do valor informativo dos dados neles contidos.

Pode-se enxergar, a partir desse conceito, documento em sentido estrito, singularizandose nos livros, folhetos, revistas, relatórios etc, bem como em sentido amplo, caracterizado como bem cultural, ou seja, monumento, sítio paisagístico, entre outros (TANUS, RENAU e ARAÚJO, 2012, p. 162).

Para a biblioteconomia especializada (aquela ligada à documentação em si, ao invés da biblioteca enquanto espaço físico), o conceito de documento, longe de ser unanimidade, é amplo, não se restringindo, consequentemente, aos livros. São diversos os gêneros documentais: textuais (manuscritos, datilografados e impressos), cartográficos (p. ex. mapas, plantas, perfis etc.), iconográficos (p. ex. fotografias, gravuras, partituras), filmográficos, sonoros (discos, fitas audiomagnéticas), micrográficos e informáticos.

Para o Arquivo Nacional (BRASIL, 2005, p. 73), documento é uma “unidade de registro de informações, qualquer que seja o suporte ou formato”. Conforme mencionado por Merlo e Konrad (2015, p. 29),

o fator determinante que confere a um documento a sua condição de documento arquivístico é que ele faça parte de um conjunto orgânico e cumpra uma determinada função ao ser produzido; dessa forma, qualquer ação ou acontecimento que se deve comprovar precisa de produção de um documento.

É certo que a documentação, nesse sentido mais estrito, como já retratado, perfaz-se em única fonte para análise, mas dela, seguramente, se pode extrair conteúdo necessário à 
compreensão local, nacional ou mundial de determinado fato, seja de seu texto expresso (literal) seja das suas entrelinhas ou de seu silêncio, sendo, inclusive, utilizados registros judiciais para se retrarar a história cultural. (BURKE, 2011, p. 25).

A ordem constitucional, como dito no tópico anterior, protege a documentação pública e privada. Além do caput do artigo 216 da CF, o qual enumera os elementos integrantes do patrimônio cultural, o parágrafo primeiro deste dispositivo ordena ao Poder Público, com o apoio da comunidade, a promoção e proteção do patrimônio cultural brasileiro, por meio de inventários, registros, vigilância, tombamento e desapropriação, e de outras formas de acautelamento. Além disso, o parágrafo quarto do mencionado dispositivo da CF assevera que “os danos e ameaças ao patrimônio cultural serão punidos, na forma da lei”.

Assim, o legislador fez erigir nova lei para estabelecer a Política Nacional de Arquivos Públicos e Privados. A Lei n ${ }^{\circ} 8.159$ de 8 de janeiro de 1991 assevera, novamente, ser dever do Poder Público a gestão documental e a proteção especial a documentos de arquivos, como instrumento de apoio à cultura (art. $1^{\circ}$ ), incumbência e gerência que se estudará a seguir.

Necessário notabilizar que o Plano Nacional de Cultura, instituído pela Lei no 12.343 de 2010, cuja duração é de dez anos, estabeleceu como princípios o direito à informação e à memória (art. $1^{\circ}$, incisos V e VI) e como objetivos, dentre outros, a proteção e promoção do patrimônio histórico material, como os documentos, bem como a promoção do direito à memória por meio dos museus, arquivos e coleções.

O parágrafo $2^{\circ}$ do art. 216 da CF/88 prescreve que “cabem à administração pública, na forma da lei, a gestão da documentação governamental e as providências para franquear sua consulta a quantos dela necessitem”. O constituinte, nesse diapasão, foi assertivo quanto à responsabilidade pela proteção da documentação cultural.

Corroborando tal colocação, a CF/88, no seu art. 23, inciso III e IV, dispõe ser “competência comum da União, dos Estados, do Distrito Federal e dos Municípios: [...] III proteger os documentos, as obras e outros bens de valor histórico, artístico e cultural, os monumentos, as paisagens naturais notáveis e os sítios arqueológicos” e todos estes podem legislar sobre a matéria, a fim de que se possa haver efetiva proteção.

Não de outra forma, em âmbito criminal, a Lei ${ }^{\circ} 9.605$ de 1998, em seus arts. 62 e seguintes, trouxe um arcabouço de delitos aos quais buscam proteger o bem jurídico difuso tutelado na espécie: o meio ambiente, especificamente em seu aspecto cultural. 
Desta feita, as ações de destruir, inutilizar ou deteriorar arquivo, registro, museu, biblioteca, pinacoteca, instalação científica ou similar são punidas com um a três anos de reclusão (art. 62, inciso II, da Lei dos Crimes Ambientais), protegendo-se não apenas a edificação, como também o acervo completo.

Trata-se, por conseguinte, de mera exemplificação da proteção ao patrimônio cultural em viés penal, vez que também são suscetíveis o administrador e gestores de arquivo, em geral, as responsabilizações civis e administrativas decorrentes da má utilização e conservação da documentação, já que necessária a preservação da herança cultural e testemunho nacional.

Por meio deles a humanidade vem a "conhecer suas raízes, compreender os problemas existentes em sua comunidade e se tornar um agente das mudanças necessárias para o melhoramento da vida social, sendo capaz de promover o bem-estar de todos dentro da comunidade” (ALVES e SANTOS, 2017, p. 168-169).

A edificação da memória, discorrida alhures, se dá, dentre outros modos, através da documentação, que necessita estar ordenada e acessível. Essa composição "se correlaciona fortemente ao acesso à informação, neste sentido, entende-se que o acesso à informação é a base para a construção da memória. [...] O acesso se torna moroso ou inexistente quando os registros informacionais não estão ordenados, o que dificulta sua acessibilidade” (MERLO e KONRAD, 2015, p. 34-35).

Interessa, portanto, uma visão mais específica da gestão documental, buscando trazer à baila o acesso às documentações públicas e privadas que dão ensejo à construção da memória, enquanto patrimônio cultural.

3. Gestão documental: conceitos, legislação e acesso aos arquivos públicos e privados.

A crescente produção de documentos pela sociedade e a sua consequente acumulação são problemas a serem enfrentados em âmbito estatal. Em razão disso, a administração pública, baseando-se nos princípios a ela inerentes (legalidade, impessoalidade, moralidade, publicidade e eficiência), insculpidos no art. 37 da Carta da República, deve buscar mecanismos para gerir esse arsenal.

A Constituição Federal de 1988 (art. 216, §2º) assevera: “cabem à administração pública, na forma da lei, a gestão da documentação governamental e as providências para franquear sua consulta a quantos dela necessitem”, motivo pelo qual, para cumprir o 
mandamento constitucional, o legislador ordinário editou as Leis n ${ }^{\circ}$ 8.159/1991(Lei da Política Nacional de Arquivos Públicos e Privados), 12.527/2011 (Lei de Acesso às informações), entre outras.

Tudo pode ser arquivado e os arquivos constituem a memória da nação, esta integrante do patrimônio cultural. A gestão documental, assim, é um conjunto de normas, procedimentos e métodos de trabalho que permitem a tramitação, produção, avaliação, uso e arquivamento de documentos oficiais. Suas principais funções são: fornecer evidências, conduzir de modo transparente as atividades e o controle de informações.

A Lei $n^{\circ}$ 8.159/1991 (Lei da Política Nacional de Arquivos Públicos e Privados) dispõe, em seu art. $3^{\circ}$, que “considera-se gestão de documentos o conjunto de procedimentos e operações técnicas referentes à sua produção, tramitação, uso, avaliação e arquivamento em fase corrente e intermediária, visando a sua eliminação ou recolhimento para guarda permanente”.

O Dicionário de Terminologia Arquivística do Conselho Nacional de Arquivos CONARQ expõe que gestão documental é o “conjunto de medidas e rotinas visando à racionalização e eficiência na criação, tramitação, classificação e avaliação dos documentos”.

Nessa sequência, a gestão cobre toda a vida do documento, desde a sua produção até a sua destinação final, sendo este um processo de eliminação ou recolhimento ao arquivo permanente, no intuito de garantir, de modo eficaz, a produção, administração, manutenção e destinação de documentos, de forma racional e econômica.

O objetivo da gestão documental é garantir, de modo eficaz, a produção, administração, manutenção e destinação dos documentos, observando-se, ainda, o menor custo para a administração pública ou particular. Trabalha a gestão, é salutar a ressalva, não somente com a destinação (guarda ou descarte), mas com a criação de mecanismos para evitar que sejam elaborados documentos não essenciais, bem como aqueles imprescindíveis para evitar a burocratização das atividades.

“Gestão documental”, afirmam Gerlane Alves e Eliete Santos (2017, p. 159), “passou a ser vista como uma forma indispensável de organização de arquivos em que, dentre as várias vantagens para a instituição, seria capaz de racionalização dos espaços”, completando, de modo acertado, que “a gestão documental não deve ser vista como uma forma5 estática que contribua 
apenas para o campo da arquivística, deve ser compreendida em toda a sua interdisciplinaridade”.

Memória é informação selecionada e organizada, cuja seleção é realizada pela humanidade. Desta feita, impossível seria, de modo físico, guardar todos os documentos produzidos pela sociedade, necessitando, portanto, de seleção e, consequentemente, de eliminação, ponto importante a ser discutido.

A Lei $n^{\circ}$ 5.433/1968, datada da época da ditadura militar brasileira, regula a microfilmagem de documentos oficiais. O tempo era, portanto, de microfilmagem. Ficou autorizada a microfilmagem de documentos particulares e oficiais arquivados, independentemente se da federação, dos estados ou dos municípios, podendo, após o procedimento, serem os documentos incinerados ou destruídos por outro meio (art. $1^{\circ}, \S 2^{\circ}$ ). No entanto, fez uma ressalva: os documentos de valor histórico não deverão ser eliminados (art. $2^{\circ}$ ). Ressalte-se, que valor histórico é, de longe, um dos conceitos mais subjetivos.

Avante, em 1991, surge na ordem jurídica a Lei nº 8.159 (Lei da Política Nacional de Arquivos Públicos e Privados) que incumbe, em mais uma ocasião, “ao Poder Público a gestão documental e a proteção especial a documentos de arquivos, como instrumento de apoio à administração, à cultura, ao desenvolvimento científico e como elementos de prova e informação” (art. $\left.1^{\circ}\right)$.

Para a mencionada Lei dos arquivos, estes são “os conjuntos de documentos produzidos e recebidos por órgãos públicos, instituições de caráter público e entidades privadas, em decorrência do exercício de atividades específicas, bem como por pessoa física, qualquer que seja o suporte da informação ou a natureza dos documentos” (art. $2^{\circ}$ ). Essas determinações constam de suas disposições gerais.

Existem arquivos públicos (Arquivo Nacional, Arquivo Público do Estado do Amazonas, Arquivo do Tribunal de Justiça do Estado do Amazonas, entre outros) e privados (arquivos pessoais, arquivos de igrejas, instituições de ensino, comerciais de empresas, etc.).

No que tange aos arquivos públicos, a Lei $\mathrm{n}^{\circ}$ 8.159/1991 os apresenta como "os conjuntos de documentos produzidos e recebidos, no exercício de suas atividades, por órgãos públicos de âmbito federal, estadual, do Distrito Federal e municipal em decorrência de suas funções administrativas, legislativas e judiciárias” (art. $7^{\circ}$ ), como por exemplo o Arquivo 
Nacional, o Arquivo Público do Estado do Amazonas e o Arquivo do Tribunal de Justiça do Estado do Amazonas.

Classificam-se os documentos públicos como correntes, intermediários e permanentes. Correntes são aqueles em curso ou que, mesmo sem movimentação, constituam objeto de consultas frequentes. Intermediários são aqueles que, não sendo de uso corrente nos órgãos produtores, por razões de interesse administrativo, aguardam a sua eliminação ou recolhimento para guarda permanente. Já permanentes correspondem aos conjuntos de documentos de valor histórico, probatório e informativo que devem ser definitivamente preservados.

Nos documentos de valor permanente, consequentemente, estão as atenções deste estudo, vez que representam os arquivos propriamente ditos e são matéria-prima da história. Após decidir-se pelo seu recolhimento em arquivo, devido ao seu conteúdo histórico, probatório e informativo, gozam de inalienabilidade e imprescritibilidade.

É de se advertir que a Lei $n^{0} 5.433 / 1969$, bem como o seu Decreto regulamentador, possibilitam a eliminação de documentos, após a microfilmagem, mas isso somente pode ocorrer em consonância com a tabela de temporalidade do órgão, respeitando-se o disposto no art. $9^{\circ}$ da Lei $n^{\circ}$ 8.159/1991 (Lei dos Arquivos) ${ }^{2}$.

Assim, cada órgão tem tabela de temporalidade documental, a citar o Tribunal de Contas da União, os Institutos Federais de Ensino Superior (IFES). Além disso, o art. 21 da Lei n ${ }^{\circ}$ 8.159/1991 define que os critérios de organização, vinculação e gestão dos arquivos dos estados, do Distrito Federal e municípios.

Necessário, nesse sentido, estabelecer o acesso às documentações de arquivos, ponto de embate ainda no cenário hodierno. Quem detém a guarda de documentos, por vezes, age em interesse pessoal, ainda que deles devam usufruir todos os cidadãos deste país. A construção da história é objeto de desejo e obstrução. Os capítulos dos estudos históricos podem trazer consequências as quais as autoridades administrativas, legislativas e judiciais não almejem.

A informação sob a guarda estatal é sempre pública, devendo a restrição ser medida de exceção. $\mathrm{O}$ acesso permite o fortalecimento da democracia, trazendo o cidadão a participar da vida do Estado, controlá-lo e conhecer seus direitos essenciais.

\footnotetext{
${ }^{2}$ Art. $9^{\circ}$ - A eliminação de documentos produzidos por instituições públicas e de caráter público será realizada mediante autorização da instituição arquivística pública, na sua específica esfera de competência”. Diz mais a Lei, em seu art. $10^{\circ}$ : "os documentos de valor permanente são inalienáveis e imprescritíveis”.
} 
A Declaração Universal dos Direitos Humanos, em seu art. 19, estabelece que "toda pessoa tem direito à liberdade de opinião e expressão; este direito inclui a liberdade de, sem interferência, ter opiniões e de procurar, receber e transmitir informações e idéias por quaisquer meios e independentemente de fronteiras”.

A informação, aliás, ajuda a combater a corrupção e trata-se de um direito fundamental, tendo a própria Declaração Interamericana de Princípios de Liberdade de Expressão, em seu item 4, disposto dessa maneira ${ }^{3}$.

Relativamente ao acesso no Brasil, a Constituição Federal brasileira dispõe em seu art. $5^{\circ}$, inciso XXXIII, que “todos têm direito a receber dos órgãos públicos informações de seu interesse particular, ou de interesse coletivo ou geral, que serão prestadas no prazo da lei, sob pena de responsabilidade, ressalvadas aquelas cujo sigilo seja imprescindível à segurança da sociedade e do Estado”.

No mesmo sentido, o art. 216 da CF, ao dispor sobre o patrimônio cultural, assevera em seu parágrafo $2^{\circ}$ que “cabem à administração pública, na forma da lei, a gestão da documentação governamental e as providências para franquear sua consulta a quantos dela necessitem”.

Infraconstitucionalmente, a Lei dos Arquivos Públicos e Privados, de 1991, estabelece:

Art. $4^{\text {o }}$ - Todos têm direito a receber dos órgãos públicos informações de seu interesse particular ou de interesse coletivo ou geral, contidas em documentos de arquivos, que serão prestadas no prazo da lei, sob pena de responsabilidade, ressalvadas aquelas cujos sigilo seja imprescindível à segurança da sociedade e do Estado, bem como à inviolabilidade da intimidade, da vida privada, da honra e da imagem das pessoas.

Art. $5^{\circ}$ - A Administração Pública franqueará a consulta aos documentos públicos na forma desta Lei.

As disposições específicas desta Lei quanto ao acesso e sigilo dos documentos públicos, no entanto, foram revogadas pela Lei de Acesso à Informação (LAI) (Lei no 12.527/2011). A LAI tem o fito de estabelecer procedimentos para tal acesso, em cumprimento ao mandamento constitucional, textualmente certificar que "é dever do Estado garantir o direito de acesso à

\footnotetext{
${ }^{3}$ 4. O acesso à informação em poder do Estado é um direito fundamental do indivíduo. Os Estados estão obrigados a garantir o exercício desse direito. Este princípio só admite limitações excepcionais que devem estar previamente estabelecidas em lei para o caso de existência de perigo real e iminente que ameace a segurança nacional em sociedades democráticas.
} 
informação, que será franqueada, mediante procedimentos objetivos e ágeis, de forma transparente, clara e em linguagem de fácil compreensão” (art. 5º).

Subordinam-se ao regime desta Lei não somente os órgãos públicos de todos os Poderes da República, incluindo Cortes de Contas, Ministério Público, autarquias, fundações e empresas públicas, entre outros, mas também as entidades privadas sem fins lucrativos que recebam para realização de ações de interesse público.

A informação pode transformar-se em conhecimento e controle, principalmente das atividades estatais, tendem a gerar administrações mais transparentes e eficientes e cidadãos mais conscientes. É por meio da informação que traçamos metas e verificamos experiências, por isso as previsões da Lei $n^{\circ} 12.527 / 2011^{4}$.

Com fins conceituais, a Lei de Acesso à Informação considera como informação “dados, processados ou não que podem ser utilizados para produção e transmissão de conhecimento, contidos em qualquer meio, suporte ou formato" (art. $\left.4^{\circ}, \mathrm{I}\right)$. Documento, por sua vez, é a “unidade de registro de informações, qualquer que seja o suporte ou formato” (art. $\left.4^{\mathrm{o}}, \mathrm{II}\right)$.

Cria-se, desta feita, a cultura do acesso, como deseja a Carta da República de 1988. Assim, o requerimento de qualquer cidadão para que tenha acesso às informações que desejar é visto como legítimo, sem necessidade de justificativa, aumentando sua confiança na gestão pública.

Portanto, com esta Lei, o Brasil abre espaço ainda maior para a transparência, consolidando o marco regulatório sobre o acesso à informação pública e privada, estabelecendo procedimentos para que a Administração responda às demandas de cidadãos, definindo, vez por todas, que a informação pública é a regra e o sigilo, a exceção.

Não se pode esquecer que o acesso encontra(va) não apenas obstáculos legais, mas também a precária situação das instituições arquivísticas, quanto às edições de regulamentações, espaço físico e pessoal preparado para utilizar os instrumentos de pesquisa necessários ao pleno acesso aos documentos.

\footnotetext{
${ }^{4}$ Em especial, o Art. $3^{\circ}$ da referida Lei: “Art. $3^{\circ}$. Os procedimentos previstos nesta Lei destinam-se a assegurar o direito fundamental de acesso à informação e devem ser executados em conformidade com os princípios básicos da administração pública e com as seguintes diretrizes:

I - observância da publicidade como preceito geral e do sigilo como exceção;

II - divulgação de informações de interesse público, independentemente de solicitações;

III - utilização de meios de comunicação viabilizados pela tecnologia da informação;

IV - fomento ao desenvolvimento da cultura de transparência na administração pública;

V - desenvolvimento do controle social da administração pública”.
} 
No entanto, ressalta Neide Sordi (2012, p. 4),

embora a Constituição Federal e todos esses diplomas legais protejam o acesso à informação, o exercício deste direio no Brasil ainda enfrentará desafios para a sua efetividade. A longa espera de um cidadão pela decisão de um processo de revisão de benefício previdenciário; a busca por informações pelos familiares desaparecidos durante o regime militar; as testativas sucessivas de se obter informações de qualquer natureza junto a uma concessionária de serviço público são exemplos da dificuldade de acesso à informação pública.

No concernente ao sigilo, este é também determinado na Lei $n^{0} 12.527 / 2011$ e é estabelecido por diversas causas a que a lei definiu (art. 23) ${ }^{5}$. Advirta-se que:

Art. 21. Não poderá ser negado acesso à informação necessária à tutela judicial ou administrativa de direitos fundamentais.

Parágrafo único. As informações ou documentos que versem sobre condutas que impliquem violação dos direitos humanos praticada por agentes públicos ou a mando de autoridades públicas não poderão ser objeto de restrição de acesso.

Para a Lei, informação sigilosa é "aquela submetida temporariamente à restrição de acesso público em razão de sua imprescindibilidade para a segurança da sociedade e do Estado”. Deve, segundo a Lei, ser obedecido o prazo máximo para cada informação, contados de sua produção, sendo: de 25 anos para aquelas classificadas como ultrassecretas, podendo ser prorrogado por igual período, de 15 anos para as consideradas secretas e de 5 anos para as reservadas (art. 24, $\S 1^{\circ}$, da Lei $\mathrm{n}^{\circ} 12.527 / 2011$ ).

Tais classificações em ultrassecreto, secreto e reservado podem ser feitas pelo Presidente e Vice-Presidente da República, por Ministros de Estado ou equivalentes,

\footnotetext{
${ }^{5}$ Art. 23. São consideradas imprescindíveis à segurança da sociedade ou do Estado e, portanto, passíveis de classificação as informações cuja divulgação ou acesso irrestrito possam:

I - pôr em risco a defesa e a soberania nacionais ou a integridade do território nacional;

II - prejudicar ou pôr em risco a condução de negociações ou as relações internacionais do País, ou as que tenham sido fornecidas em caráter sigiloso por outros Estados e organismos internacionais;

III - pôr em risco a vida, a segurança ou a saúde da população;

IV - oferecer elevado risco à estabilidade financeira, econômica ou monetária do País;

V - prejudicar ou causar risco a planos ou operações estratégicos das Forças Armadas;

VI - prejudicar ou causar risco a projetos de pesquisa e desenvolvimento científico ou tecnológico, assim como a sistemas, bens, instalações ou áreas de interesse estratégico nacional;

VII - pôr em risco a segurança de instituições ou de altas autoridades nacionais ou estrangeiras e seus familiares; ou

VIII - comprometer atividades de inteligência, bem como de investigação ou fiscalização em andamento, relacionadas com a prevenção ou repressão de infrações.
} 
Comandantes da Marinha, do Exército e da Aeronáutica, Chefes de Missões Diplomáticas e Consulares permanentes no exterior, nos termos do art. 27, incisos I a III, da Lei de Acesso à Informação.

Percebe-se que, quando em questão a legislação arquivística, a ênfase maior é no sigilo dos documentos. No dizer de Georgete Rodrigues (2011, p. 257), “o poder político tem adotado uma postura preferencialmente "reativa” quando confrontado às demandas de acesso aos arquivos, em vez de formular, de fato, uma política arquivística”.

O segredo dos documentos, ainda que em um período de tempo, busca o esquecimento ou a perda do foco na questão segregada. A finalidade dos arquivos, segundo Rodrigues (2011, p. 262), “é, justamente, de conjurar essa ameaça de “apagamento”, pois eles instituem a marca material do vivido, do sofrido, do testemunhado. E o arquivo é linguagem, discurso, portanto sempre comunica algo para alguém: é portador e suporte de mensagens”.

É de se relembrar que, ao final de seu governo, Fernando Henrique Cardoso (FHC), por meio do Decreto $\mathrm{n}^{\circ} 4.553$ de 2002, estabeleceu a possibilidade de sigilo eterno a alguns documentos públicos. Esta determinação somente teve fim com o advento da Lei $\mathrm{n}^{\circ}$ 12.527/2011. O governo de FHC, a bem da verdade, editara diversos Decretos com o cunho de reforçar o sigilo de documentos públicos, podendo-se comprovar pelo quadro abaixo, reproduzido da obra de Georgete Rodrigues (2011, p. 272):

Quadro 1: Leglslação relaclonada aos arqulvos (1997-2002)

\begin{tabular}{|c|c|c|}
\hline $\begin{array}{l}\text { Presidente } \\
\text { da } \\
\text { República }\end{array}$ & Legislaçāo & Particularidades \\
\hline \multirow{8}{*}{$\begin{array}{c}\text { Presidente } \\
\text { Fernando } \\
\text { Henrique } \\
\text { Cardoso } \\
(1995- \\
2002)\end{array}$} & $\begin{array}{l}\text { Decreto n. } 2.134 \text {, } \\
\text { de } 24 \text { de janeiro de } 1997\end{array}$ & $\begin{array}{l}\text { Ênfase no sigilo. Introduz as Comissões Permanentes } \\
\text { de Acesso. Restrições ao pesquisador }\end{array}$ \\
\hline & $\begin{array}{l}\text { Decreto n. } 2.182 \text {, } \\
\text { de } 20 \text { de março de } 1997\end{array}$ & $\begin{array}{l}\text { Normatiza transferência e tratamento dos acervos. } \\
\text { Estabelece prazo para a criação das Comíssóes } \\
\text { Permanentes de Avaliação de Documentos }\end{array}$ \\
\hline & $\begin{array}{l}\text { Leil } n .9 .507 \text {, } \\
\text { de } 12 \text { de novembro de } 1997\end{array}$ & $\begin{array}{l}\text { Regula o direito de acesso a informaçōes e disciplina } \\
\text { o rito processual do habeas data }\end{array}$ \\
\hline & $\begin{array}{l}\text { Decreto n. } 2.910 \text {, } \\
\text { de } 29 \text { de dezembro de } 1998\end{array}$ & $\begin{array}{l}\text { Ênfase no sigilo. Mantém as Comissões Permanentes } \\
\text { de Avaliação de Documentos }\end{array}$ \\
\hline & $\begin{array}{l}\text { Decreto n. 3.505, } \\
\text { de } 13 \text { de junho de } 2000\end{array}$ & $\begin{array}{l}\text { Institui a política de segurança da informação (dados } \\
\text { informatizados) }\end{array}$ \\
\hline & $\begin{array}{l}\text { Decreto n. } 4.073 \text {, } \\
\text { de } 3 \text { de janeiro de } 2002\end{array}$ & $\begin{array}{l}\text { Institui as Comissões Permanentes de Avaliação de } \\
\text { Documentos }\end{array}$ \\
\hline & $\begin{array}{l}\text { Decreto n. } 4.497 \text {, } \\
\text { de } 4 \text { de dezembro de } 2002\end{array}$ & Ênfase no sigilo \\
\hline & $\begin{array}{l}\text { Decreto n. } 4.553 \text {, } \\
\text { de } 27 \text { de dezembro de } 2002\end{array}$ & $\begin{array}{l}\text { Ênfase no sigilo. Institui as Comissões Permanentes } \\
\text { de Avaliação de Documentos Sigilosos nos órgãos } \\
\text { públicos. Sigilo eterno }\end{array}$ \\
\hline
\end{tabular}

No governo de Luís Inácio Lula da Silva (2003-2010), Georgete Rodrigues (2011, p. 277) elabora o seguinte quadro sobre a legislação de arquivos: 


\begin{tabular}{|c|c|c|}
\hline \multirow{6}{*}{$\begin{array}{l}\text { Presidente } \\
\text { Luís } \\
\text { Inácio } \\
\text { Lula } \\
\text { da Silva } \\
\text { (2003- } \\
\text { 2010) }\end{array}$} & $\begin{array}{l}\text { Decreto } n \text {. } \\
4.850, \text { de } \\
2 \text { de outubro } \\
\text { de } 2003\end{array}$ & $\begin{array}{l}\text { Institui comissão interministerial com a finalidade de obter } \\
\text { informações e a localização dos mortos na Guerrilha do Araguaia }\end{array}$ \\
\hline & $\begin{array}{l}\text { Decreto } n \text {. } \\
5.301 \text {, de } 9 \\
\text { de dezembro } \\
\text { de } 2004\end{array}$ & $\begin{array}{l}\text { Regulamenta o acesso aos documentos públicos, ressalvadas os } \\
\text { desigiloparasegurançada sociedadee doEstado. Instituia Comissão } \\
\text { de Averiguação e Análise de Informaçoes Sigilosas na Casa Civil } \\
\text { da Presidência da República }\end{array}$ \\
\hline & $\begin{array}{l}\text { Medida } \\
\text { Provisória n. } \\
228 \text {, de } 9 \\
\text { de dezembro } \\
\text { de } 2004\end{array}$ & $\begin{array}{l}\text { Retoma os prazos de acesso da Lei de Arquivos n. } 8.159 \text {, de } \\
\text { janeiro de } 1991 \text {. Reforça o papel da Comissão de Averiguação e } \\
\text { Análise de Informaçóes Sigilosas }\end{array}$ \\
\hline & $\begin{array}{l}\text { Lei n. } 11.111 \\
\text { de } 5 \text { de maio } \\
\text { de } 2005\end{array}$ & $\begin{array}{l}\text { Define a composição da Comissão de Averiguação e Análise de } \\
\text { Informações Sigilosas e a sua metodologia de trabalho }\end{array}$ \\
\hline & $\begin{array}{l}\text { Decreto } n . \\
5.584, \text { de } 18 \\
\text { de novembro } \\
\text { de } 2005\end{array}$ & $\begin{array}{l}\text { Recolhimento ao Arquivo Nacional dos documentos arquivísticos } \\
\text { públicos produzidos e recebidos pelos extintos Conselho de } \\
\text { Segurança Nacional (CSN), Comissão Geral de Investigaçóes } \\
\text { (CGI) e Serviço Nacional de Informaçóes (SNI), que estejam sob a } \\
\text { custódia da Agência Brasileira de Inteligência (ABIN) }\end{array}$ \\
\hline & $\begin{array}{l}\text { PL n. } 5.228 \text {, } \\
\text { de } 13 \text { de maio } \\
\text { de } 2009 \text {. }\end{array}$ & $\begin{array}{l}\text { Regula o acesso a informações previsto no inciso XXXIII do } \\
\text { art. } 5^{\circ} \text {, no inciso II do } \$ 3^{\circ} \text { do art. } 37 \text { e no } \$ 2^{\circ} \text { do art. } 216 \text { da } \\
\text { Constituição, no âmbito da Administração Pública Federal, e dá } \\
\text { outras providências }\end{array}$ \\
\hline
\end{tabular}

No que diz respeito aos arquivos privados e seu consequente acesso, o Decreto $n^{\circ} 4.073$ de 2002, que regulamenta a Lei $n^{\circ} 8.159$ de 1991, expõe, em seu art. 22, que “os arquivos privados de pessoas físicas ou jurídicas que contenham documentos relevantes para a história, a cultura e o desenvolvimento nacional podem ser declarados de interesse público e social por decreto do Presidente da República”.

O Decreto assevera que “a declaração de interesse público e social de que trata este artigo não implica a transferência do respectivo acervo para guarda em instituição arquivística pública, nem exclui a responsabilidade por parte de seus detentores pela guarda e a preservação do acervo" (art. 22, $\S 1^{\circ}$ ).

Automaticamente, quando da edição do Decreto, foram considerados documentos privados de interesse público e social, conforme o art. 22, §2:

Art. 22. (...)

I - os arquivos e documentos privados tombados pelo Poder Público;

II - os arquivos presidenciais, de acordo com o art. 3o da Lei no 8.394, de 30 de dezembro de 1991;

III - os registros civis de arquivos de entidades religiosas produzidos anteriormente à vigência da Lei no 3.071, de 1 o de janeiro de 1916, de acordo com o art. 16 da Lei no 8.159, de 1991. 
Após o procedimento estabelecido no Decreto em comento, para declaração de interesse público e social de um arquivo privado, além da responsabilidade de preservação por parte seus proprietários ou detentores,

a alienação de arquivos privados declarados de interesse público e social deve ser precedida de notificação à União, titular do direito de preferência, para que manifeste, no prazo máximo de sessenta dias, interesse na aquisição, na forma do parágrafo único do art. 13 da Lei no 8.159, de 1991. (art. 25).

A Lei $n^{0} 8.394$ de 1991, que dispõe sobre a preservação, organização e proteção dos acervos documentais dos presidentes da República, explicita que, embora “os documentos que constituem o acervo presidencial privado são na sua origem, de propriedade do Presidente da República, inclusive para fins de herança, doação ou venda” (art. $2^{\circ}$ ), “os acervos documentais privados dos presidentes da República integram o patrimônio cultural brasileiro e são declarados de interesse público para os fins de aplicação do $\S 1^{\circ}$ do art. 216 da Constituição Federal”.

Por conseguinte, embora constituindo patrimônio privado, mas ao mesmo tempo de interesse social, a preferência em caso de venda é da União, bem como a alienação não poderá ocorrer sem a manifestação desta, uma vez que os bens são integrantes do patrimônio cultural do Brasil.

O acesso, nesses casos, é possível, embora este fique sujeito aos dispositivos legais que regulam a segurança do Estado. Isto porque o sistema de acervos documentais privados dos presidentes da República terá como objetivo, segundo a Lei nº 8.394/1991:

Art. $6^{\circ} .(\ldots)$

III - manter referencial único de informação, capaz de fornecer ao cidadão, de maneira uniforme e sistemática, a possibilidade de localizar, de ter acesso e de utilizar os documentos, onde quer que estejam guardados, seja em entidades públicas, em instituições privadas ou com particulares, tanto na capital federal como na região de origem do Presidente ou nas demais regiões do País.

Resta evidente que, ainda que de natureza privada, o acesso aos arquivos é possibilitado, quando estiver presente interesse público, como no caso dos arquivos da Presidência da República, sem olvidar, por conseguinte, dos critérios de segurança nacional. Não se aborda, 
momentaneamente, as subjetividades e possibilidades obscuras de, sob o pretexto da 'segurança nacional', prescrever o sigilo por motivos, na realidade, escusos, o que poderá ensejar a escrita de novos estudos.

\section{CONCLUSÃO}

A informação tem chego aos poucos ao cidadão comum, apesar das dificuldades inerentes a um Estado com desigualdades tão grandes quando sua extensão territorial, somada à uma enorme carga burocrática. Desse modo, com a Lei de Acesso à Informação, que é marco de transparência no Brasil, o patrimônio cultural tem tomado novos contornos desde o DecretoLei $n^{\circ}$ 25/1937 e passando-se, necessariamente pelos ditames constitucionais.

A memória, restou clarividente, possui assento no rol de bens culturais, e é lugar de desejo e disputa. Fazê-la através de documentos (cartas, ofícios, processos judiciais etc) é imperioso. Documentos estes que devem ser dotados de autenticidade e guardados em lugares capazes de conservá-los pelo seu período máximo de existência.

O debate sobre a memória e sua preservação, entretanto, precisa ser aberto amplamente. É necessário que, nas propostas legislativas, chame-se à mesa de discussão especialistas na área, inclusive entidades como o Conselho Nacional dos Arquivos (CONARQ), a fim de estabelecer parâmetros, inclusive, de digitalização responsável dos documentos históricos.

No entanto, enquanto não se tem segurança para estabelecer outros parâmetros de guarda documental, é imprescindível que o documento se mantenha incólume, em arquivos e centros de memória capazes de permitir o acesso e a conservação, discutindo-se as reduções de custos e problemas socioambientais de modo menos pragmático e mais cauteloso, por todos os motivos discorridos. Assim, os arquivos físicos ainda são a principal maneira de preservação documental e devem ser mantidos até que um meio com o máximo de eficiência venha a surgir.

Há, por fim, que se trazer os debates para a sociedade, fazendo com que a memória e, consequentemente, os documentos históricos sejam preservados de modo seguro e em plataformas físicas ou digitais confiáveis e com o máximo de conservação, a fim de que não se possa maquiar a história, nem se perder o controle das atividades estatais ao longo do tempo.

Os desassossegos são próprios da pesquisa e motivam a continuidade deste processo investigativo do tema da memória e da documentação, principalmente relacionada aos arquivos judiciais. Constata-se, portanto, que muito embora a Constituição Federal de 1988 tenha 
ordenado que o patrimônio cultural seja tratado como direito fundamental, os instrumentos criados pelo legislador são pouco aplicados, além de preverem subjetividades e discricionaridades largas aos servidores de arquivos.

\section{REFERÊNCIAS BIBLIOGRÁFICAS}

ALVES, Gerlane F. SANTOS, Eliete C. A gestão documental no IPHAN-PB: contribuição para a preservação da memória. Biblionline. João Pessoa, v. 13, n. 1, p. 156-170, jan./mar., 2017. (Disponível

em:

http://periodicos.ufpb.br/ojs2/index.php/biblio/article/download/31641/17816. Acesso em 19 de jul. de 2017).

BRASIL. ARQUIVO NACIONAL. Dicionário Brasileiro de Terminologia Arquivística. Rio de Janeiro: Arquivo Nacional, 2005. (Disponível em: http://www.arquivonacional.gov.br/images/pdf/Dicion_Term_Arquiv.pdf. Acesso em: 10 de BRASIL. Lei $\mathrm{n}^{\mathbf{0}}$ 5.433, de 8 de maio de 1968. Regula a microfilmagem de documentos oficiais e dá outras providências. (Disponível em: http://www.planalto.gov.br/ccivil_03/leis/L5433.htm. Acesso em: 10 de jan. de 2018).

\section{Constituição (1988). Constituição da República Federativa do Brasil:}

promulgada em 05 de outubro de 1988. (Disponível em: http://www.planalto.gov.br/ccivil_03/constituicao/constituicaocompilado.htm. Acesso em 30 de dez. de 2016).

. Lei $\mathbf{n}^{\circ}$ 8.159, de 8 de janeiro de 1991. Dispõe sobre a política nacional de arquivos públicos e privados e dá outras providências. (Disponível em: http://www.planalto.gov.br/ccivil_03/leis/18159.htm. Acesso em 30 de dez. de 2017).

. Lei n⿳0 8.394, de 30 de dezembro de 1991. Dispõe sobre a preservação, organização e proteção dos acervos documentais privados dos presidentes da República e dá outras providências. (Disponível em: http://www.planalto.gov.br/ccivil_03/leis/L8394.htm. Acesso em: 10 de jan. de 2018).

Lei $n^{0}$ 9.605, de 12 de fevereiro de 1998. Dispõe sobre as sanções penais e administrativas derivadas de condutas e atividades lesivas ao meio ambiente, e dá outras 
providências. (Disponível em: http://www.planalto.gov.br/ccivil_03/leis/L9605.htm. Acesso em 08 de fev. de 2017).

Decreto $\mathbf{n}^{\mathbf{0}}$ 4.073, de 3 de janeiro de 2002. Regulamenta a Lei no 8.159, de 8 de janeiro de 1991, que dispõe sobre a política nacional de arquivos públicos e privados. (Disponível em: http://www.planalto.gov.br/ccivil_03/decreto/2002/d4073.htm. Acesso em: 10 de jan. de 2018).

Lei $\mathbf{n}^{0}$ 12.527, de 18 de novembro de 2011. Regula o acesso a informações previsto no inciso XXXIII do art. 5o, no inciso II do § 30 do art. 37 e no § 2o do art. 216 da Constituição Federal; altera a Lei no 8.112, de 11 de dezembro de 1990; revoga a Lei no 11.111, de 5 de maio de 2005, e dispositivos da Lei no 8.159, de 8 de janeiro de 1991; e dá outras providências. (Disponível em: http://www.planalto.gov.br/ccivil_03/_ato2011-2014/2011/lei/l12527.htm. Acesso em 08 de fev. de 2017).

BURKE, Peter. Abertura: a nova história, seu passado e seu futuro. In: BURKE, Peter. (org.) A escrita da história: novas perspectivas. São Paulo: Editora UNESP, 2011.

GOMES, F. Araújo. Arquivo e documentação. Rio de Janeiro: [s.n.], 1967.

GUINCHART, Clarice. MENU, Michel. Introdução geral às ciências da informação e documentação. Brasília: IBICT, 1994.

LE GOFF, Jacque (1924). História e memória. Trad.: Bernardo Leitão [et al.]. Coleção Repertórios. Campinas, SP: Editora da UNICAMP, 1990. (Disponível em: http://memorial.trt11.jus.br/wp-content/uploads/Hist\%C3\%B3ria-e-Mem\%C3\%B3ria.pdf.

Acesso em: 10 de jul. de 2017).

MACHADO, Paulo Affonso Leme. Direito ambiental brasileiro. 21. ${ }^{\text {a }}$ ed. rev., ampl. e atual. São Paulo: Malheiros, 2013.

MERLO, Franciele M. KONRAD, Glaucia V. R. Documento, história e memória: a importância da preservação do patrimônio documental para o acesso à informação. Informação \& Informação. vol. 20, n. 1, p. 26-42, jan./abr., 2015. (Disponível em: http://www.uel.br/revistas/uel/index.php/informacao/issue/view/986. Acesso em: 10 de jul. de 2017).

ONU. Declaração Universal dos Direitos Humanos. 1948. (Disponível em: http://www.onu.org.br/img/2014/09/DUDH.pdf. Acesso em 08 de fev. de 2017). 
PELEGRINI, Sandra C. A. Patrimônio cultural: consciência e preservação. São Paulo: Brasiliense, 2009.

RODRIGUES, Georgete M. Legislação de Acesso aos Arquivos no Brasil: um terreno de disputas políticas pela memória e pela história. Acervo. Rio de Janeiro, v. 24, nº 1, p. 257-286, jan./jul. de 2011.

SCHELLENBERG, T. R. Arquivos modernos: princípios e técnicas. $6^{\text {a }}$ ed. Rio de Janeiro: FGV, 2006.

SOARES, Inês V. Prado. Desafios ao lidar com o legado da ditadura brasileira: e se usássemos os instrumentos protetivos dos bens culturais?. Custos Legis. vol. 4, p. 1-15, 2013.

. QUINALHA, Renan H. A memória e seus abrigos: considerações sobre os ligares de memória e seus valores de referência. Revista Anistia Política e Justiça de Transição, v. 4, p. 250-278, 2010.

SORDI, Neide A. D. de. A lei de acesso à informação pública e a gestão documental no judiciário. Anais do V Congresso Nacional de Arquivologia. Salvador/BA, 2012. (Disponível em http://www.arquivista.net/AnaisEventos/cna2012/encontros.pdf. Acesso em 16 de ago. de 2017).

TANUS, Gabrielle F. de S. C. RENAU, Leonardo V. ARAÚJO, Carlos A. A. O conceito de documento em arquivologia, biblioteconomia e museologia. In: Revista Brasileira de Biblioteconomia e Documentação. Vol. 8, n. 2. São Paulo: p. 158-174, jul/dez, 2012.

ZARANKIN, Andrés. SALERNO, Melisa. Reflexões sobre os espaços para a memória da ditadura em Buenos Aires. In: SOARES, Inês. CUREAU, Sandra. (Orgs.). Bens culturais e direitos humanos. São Paulo: Edições Sesc São Paulo, 2015. p. 259-289. 